\title{
REFORMA TRIBUTÁRIA: UMA VISÃO HISTÓRICA
}

\author{
Alcides Jorge Costa \\ Professor Titular da Faculdade de Direito da USP
}

Parece que reformas tributárias estão sempre na ordem do dia entre nós. A Constituição de 1988 , em certa medida, redesenhou o sistema tributário nacional. Decorridos apenas cinco anos de sua promulgação, já se clama por uma nova reforma, com várias propostas que alteram profundamente o sistema em vigor. Alteram profundamente sob certos aspectos, mas não sob outros, acrescento. Todas estas propostas apresentam-se com cunho de racionalidade e é claro que a têm. Mas um sistema tributário, como a forma de organização de um país, pode ser elaborado a partir de pontos de vista diferentes, cada qual baseado em uma racionalidade distinta. Mas a história, de uma forma ou de outra, sempre se faz presente na organização dos estados nacionais e, por conseqüência, de seus sistemas tributários. Como diz Gunter Schmölders' um "sistema tributário 'racional' ou 'científico formado intencionalmente conforme as idéias teóricas da coerência das coisas econômicas' não precisa em absoluto desenvolver-se a partir de um princípio básico único: ao contrário, a realidade econômica multiforme sugere a consideração de várias lógicas de ordenamento do sistema. Deste modo explica-se também que não pode existir apenas um sistema tributário racional; antes, das múltiplas possibilidades de estruturação, podem resultar múltiplos sistemas tributários" De resto, em geral "a uma alteração da estrutura do sistema da economia privada, há-de seguir-se uma modificação do modo da tributação" como diz Wagner.

Parece-me claro que as múltiplas possibilidades de estruturação sofrem a influência de fatores históricos. Neste momento, quando tanto se fala em reforma, parece útil assinalar alguns problemas cujas raízes são antigas e que ainda não encontraram soluções satisfatórias.

\footnotetext{
* Aula inaugural, proferida no Salão Nobre da Faculdade de Direito, em 28 de fevereiro de 1994.
}

1. Sistema y Sistematica Impositivos. In: Tratado de Finanzas, publicado sob a direção de W. Gerloff e F. Neumark (trad. espanhola), Buenos Aires, El Ateneo, 1961, t. 2, p. 301-2. 
Começo pela questão da Federação. O Brasil Império era centralizado e a centralização era herança do Brasil Colônia. $O$ artigo $2^{\circ}$ da Constituição de 1824 dizia que o território brasileiro "é dividido em provincias na forma em que atualmente se acha, as quais poderão ser subdivididas como pedir o bem do estado". E o artigo 165 dispunha: "Haverá em cada provincia um presidente, nomeado pelo Imperador, que o poderá remover, quando entender que assim convém ao bom serviço do Estado".

Proclamada a República, no mesmo dia foi expedido o Decreto n. 1 cujo artigo $1^{\circ}$ proclamava provisoriamente e decretava como a forma de governo da nação brasileira a República Federativa e cujo artigo $2^{\circ}$ dizia que "as províncias do Brasil, reunidas pelo laço da Federação, ficam constituindo os Estados Unidos do Brasil"

Portanto, a forma federativa nasceu de cima para baixo, por decreto. No entanto, malgrado a maneira de sua criação, a idéia de federação vinha sendo cogitada de longa data. De início, a organização do Império em províncias, às quais o Ato Adicional deu fontes próprias de receita, com assembléias provinciais que tinham um poder legislativo de certa amplitude, deu margem a que se discutisse se o Brasil Império não era constituído em federação. João Camillo de Oliveira Torres inicia o capítulo III do seu clássico livro $A$ Formação do Federalismo no Brasil, ${ }^{2}$ perguntando: "Seria o império um Estado federal, conforme a definição dada anteriormente: corpo político constituido de coletividade e, não, de individuos"?

Não cabe discutir aqui este problema. Assinalo, apenas, que hoje o Brasil Império é correntemente tido como país unitário. Assinalo, também, que a idéia da federação vinha sendo largamente discutida, quase desde a Independência. Rui Barbosa era um dos pregadores do federalismo e confessou ter aderido ao republicanismo quando se convenceu de que a monarquia se opunha definitivamente à federação. Disse ele, em discurso: "Eu era, senhores, federalista antes de ser republicano. Não me fiz republicano senão quando a evidência irrefragável dos acontecimentos me convenceu de que a monarquia se incrustava irredutivelmente na resistência à federação. Esse 'non possumus' dos partidos monárquicos foi o seu erro fatal. A mais grave responsabilidade, a meu ver, dos 
que presidiram à administração do país no derradeiro estádio do império está na opinião obsedada, inepta, criminosa de uns, na fraqueza de outros." 3

Proclamada a República e convertido o Brasil em federação, desde logo se estabeleceu grande discussão em torno da partilha das receitas tributárias entre a União e os Estados. Várias propostas foram apresentadas à Assembléia Constituinte, mas duas, realmente, centralizaram as atenções: a do Governo Provisório, certamente inspirada por Rui Barbosa e a dos adeptos de Júlio de Castilhos, a primeira buscando o fortalecimento financeiro da União e a segunda procurando fortalecer mais os Estados. Prevaleceu a primeira. Mas cito o episódio da partilha das fontes de receita apenas para introduzir um problema que nos aflige até hoje.

Sabemos que, descoberto o Brasil, foram criadas as Capitanias Hereditárias, como instrumento de colonização. Existiram, também, as Capitanias da Coroa ou Capitanias Reais, pertencentes à Coroa portuguesa e que resultaram do desmembramento ou da junção de Capitanias Hereditárias, por necessidade administrativa ou por abandono dos primitivos donatários. Ao ser proclamada a Independência, só havia Capitanias Reais: as Capitanias do Pará, Maranhão, Pernambuco, Bahia, Minas Gerais, Goiás, Mato Grosso, Rio de janeiro, São Paulo, Espírito Santo, Piauí, Rio Grande do Norte, Santa Catarina, Alagoas, Sergipe, Amazonas, Pará, Ceará, Paraíba e Paraná, esta desmembrada de São Paulo. A divisão administrativa do período colonial foi recebida pelo Império, que pouco a modificou. Do Império, quando as capitanias tornaram-se províncias, passou à República, com as províncias passando a Estados. Esta divisão não deixa de ter suscitado e de ainda suscitar problemas. Já houve quem propusesse a redivisão, para que os Estados tivessem áreas mais iguais, ao contrário do que acontece: o Amazonas tem cerca de $1.800 .000 \mathrm{~km}^{2}$ ao passo que Sergipe tem apenas 21.994 $\mathrm{km}^{2}$ de área. $\mathrm{O}$ autor da proposta a que me refiro foi Felisbelo Freire que, de modo ingênuo como assinalou João Camillo de Oliveira Torres, ${ }^{4}$ associava igualdade de área com igualdade de importância econômica.

De qualquer modo, a divisão em Estados, foi praticamente herdada da divisão em Capitanias Reais, cujos limites atendiam ao que eram ou pareciam ser as

3. Obras Completas de Rui Barbosa: a Constituição de 1891, Rio de Janeiro, Ministério da Educação e Saúde, 1946, v. 18, t. 1, p. 148.

4. Ob. cit., p. 167. 
necessidades da Coroa portuguesa. Não se pode desconhecer, porém, que, com o curso do tempo, em cada Capitania, Província ou Estado constitui-se um sentimento, um modo de ser local, o que era inevitável dada a grande extensão do Brasil. Mas já no Império, as desigualdades regionais eram grandes.

Uma vez que a organização federativa exigia que os Estados e a União tivessem suas fontes de receita - quaisquer que fossem, sem que se esqueça que, em grande medida, mais recursos significam mais poder - a primeira Constituição republicana determinou simplesmente os tributos que caberiam à União e os que caberiam aos Estados deixando àquela e a estes instituir novas fontes de receita, desde que não coincidissem com as expressamente designadas. Por outras palavras, deixou um campo residual à competência concorrente da União e dos Estados. O mesmo sistema foi mantido pelas Constituições de 1934 e 1937. Os Estados reputavam-se de igual potencialidade econômica, presunção que contrariava a realidade.

A Constituição de 1946 manteve, basicamente, o mesmo sistema, com uma novidade: a transferência de parcelas da receita privativa da União para os Estados e Municípios. Assim, da renda resultante do imposto único sobre combustíveis líquidos ou gasosos, lubrificantes, minerais do País e energia elétrica, $60 \%$ eram entregues aos Estados, ao Distrito Federal e aos Municípios, na proporção de sua respectiva superficie, população, consumo e produção, para fins estabelecidos em lei federal. Da mesma forma, a União devia entregar aos Municípios, exceto os das capitanias, $10 \%$ do produto da arrecadação do imposto de renda. Mais tarde, através da Emenda Constitucional n. 5, de 21 de novembro de 1961 , esta percentagem foi elevada para $15 \%$.

Estava inaugurada a transferência constitucional de receitas, forma de auxiliar os tesouros estaduais.

A Emenda n. 18, de 1965, instituiu os fundos de participação dos Estados e Municípios. Determinada parcela da arrecadação, pela União, do imposto de renda e do imposto sobre produtos industrializados é transferida para Estados e Municípios segundo determinados critérios.

A Constituição de 1988 conservou e ampliou os fundos de participação de Estados e Municípios. Do que arrecada a título de imposto de renda e de imposto sobre produtos industrializados, a União entrega $44 \%$ aos fundos de 
participação, mais $3 \%$ para programas de financiamento ao setor produtivo do Norte, Nordeste e Centro-Oeste.

Com esta breve exposição sobre as transferências constitucionais de receitas para os Estados - e deixo os Municípios de lado - volto às desigualdades regionais. A existência de um fundo de participação dos Estados na arrecadação da União e a maneira de rateá-lo, com obediência do artigo 161, II, da Constituição, que subordina os critérios deste rateio ao objetivo de promover o equilíbrio sócioeconômico entre os Estados é suficiente para evidenciar as desigualdades. A União arrecada muito mais em certas regiões que, proporcionalmente, têm participação menor no fundo. E, como foi dito, estes fundos são uma espécie de redistribuição de receita.

Já na primeira Constituinte republicana se disse que Estados do Nordeste não subsistiriam sem o auxílio da União. Um século decorrido, qual a situação? Em 1992, a receita disponivel do Acre provinha $10 \%$ da arrecadação própria e $90 \%$ de transferências constitucionais. Cito outros Estados. O Amapá tem $11 \%$ de receita própria e $89 \%$ de receita transferida. Roraima tem $13 \%$ e $67 \%$, respectivamente. Tocantins, $22 \%$ e $78 \%$; o Maranhão, $31 \%$ e $69 \%$; o Piauí, $34 \%$ e $66 \%$ Em suma, onze Estados, todos das regiões Norte e Nordeste, têm receita própria inferior às transferências constitucionais que a União lhes faz. Nenhum chega a ter arrecadação própria igual ou superior a $70 \%$ de sua receita total. Enquanto isto, em termos percentuais da receita tributária disponível, o Rio de Janeiro tem $92 \%$ de arrecadação própria e $8 \%$ de transferência, São Paulo $95 \%$ e $5 \%$, o Paraná $83 \%$ e $17 \%$, Minas Gerais $84 \%$ e $16 \%$, Goiás $81 \%$ e $19 \%$, para citar alguns exemplos.

Se, ao lado das transferências constitucionais, considerarmos as chamadas transferências negociadas, a disparidade é ainda maior. Mais ainda: as menores receitas próprias encontram-se nos Estados de criação recente: Acre, Amapá, Roraima e Tocantins. Apenas Rondônia escapa a esta constatação. Tira-se, desde logo, a conclusão de ter sido precipitada a criação destes Estados. E ainda se fala em novos Estados que certamente também não se sustentarão, e tudo para atender interesses pouco edificantes.

Propus-me falar de reforma tributária com uma visão histórica. É tempo de examinar as propostas existentes, pelo menos as mais conhecidas, à luz do que foi dito. As propostas podem ser divididas em dois grupos: o das que seguem 
o sistema atual para o qual apenas propõem modificações e o das que contêm sistemas radicalmente distintos do existente. Não vou referir-me às do primeiro grupo, por não introduzirem modificações substanciais e que, no assunto de que venho tratando, apontam redução dos fundos de participação de Estados e Municípios, do que decorreria maior disponibilidade de recursos para a União. Exemplo deste grupo é a proposta do deputado Luis Carlos Hauly.

No segundo grupo, incluo a proposta do deputado Flávio Rocha, a do deputado Roberto Ponte e a do dr. Ives Gandra da Silva Martins. A primeira adota a idéia do imposto único, pregada pelo economista Marcos Cintra; este imposto seria arrecadado pela União e a proposta não esclarece como seria partilhado por Estados e Municípios. O mesmo ocorre com a proposta do deputado Luiz Roberto Ponte, que mantém vários impostos, todos arrecadados pela União. Ambas as propostas podem levar à destruição da Federação ou, no mínimo, a alterações em seus contornos atuais. Ou são produto do desconhecimento da história, do problema da divisão territorial do País e das desigualdades regionais que o caracterizam, ou pretendem alterar profundamente o desenho da Federação sem, no entanto, dizerem onde pretendem chegar.

A proposta do dr. Ives Gandra mantém impostos federais, estaduais e municipais. Acrescenta que a União entregará $35 \%$ do produto da arrecadação do imposto de renda aos Estados, 25\% aos Municípios e 5\% ao Distrito Federal; notese que a União só terá os impostos de exportação e de importação, além do de renda. Os Estados ficariam com o imposto de circulação de mercadorias e serviços, de cujo produto entregariam $40 \%$ à União e $25 \%$ aos Municípios. Estes, por sua vez, ficariam com o imposto sobre a propriedade predial e territorial urbana e rural, de cujo produto entregariam $40 \%$ à União e $35 \%$ aos Estados. O projeto defere à lei complementar a definição dos critérios para esta participação recíproca. Vale dizer, omite-se quanto a estes critérios. A crítica feita aos outros projetos pode estender-se a este com pequenas variantes, no tocante ao desenho da Federação. Parece que, à luz da história, o que se deveria perguntar é se todos os Estados existentes preenchem os requisitos mínimos de autonomia para prosperarem e, se não preenchem, qual o custo que suas populações em particular e o Brasil em geral pagam em vão por uma autonomia mal-entendida.

Passo agora a outro aspecto da tributação no Brasil, com fundas raízes históricas, de conseqüências que se estendem até hoje. 
Peço-lhes que não estranhem se abordo agora a tributação da propriedade nos Estados Unidos. Como diz Shultz, ${ }^{5}$ a tributação da propriedade atingiu seu mais pleno desenvolvimento nos Estados Unidos, até a ponto de, às vezes, considerar-se o chamado general property tax uma forma de tributação puramente norte-americana. Impostos sobre a terra apareceram intermitentemente no sistema tributário das colônias norte-americanas. Nas décadas de 1790 e 1800 , os governos locais e os Estados mais novos do oeste recorreram crescentemente a este imposto. De 1815 em diante, os Estados e os governos locais ficaram mais dependentes deste imposto sobre a terra e o expandiram para um imposto geral sobre a propriedade, abrangendo não só as propriedades imóveis mas também as móveis. Durante o período da Guerra de Secessão, o imposto geral sobre a propriedade estava estabelecido como o tributo básico de Estados e poderes locais. Sem pretender fazer uma história detalhada do imposto geral sobre a propriedade, acrescento apenas que a importância deste imposto cresceu de 1900 a 1930, mas caiu no período da depressão, expandindo-se novamente depois de 1934. Mais recentemente, a importância deste tributo tem decrescido.

Outro dado importante é-nos dado pela Constituição dos Estados Unidos, que tem mais de dois séculos, em cujo artigo I, Seção, 9 lê-se:

"Não serão lançados impostos ou direitos sobre artigos exportados por qualquer Estado"

Enquanto isto, o que ocorria no Brasil?

A propriedade imobiliária rural, sobretudo, não era tributada. Como relata Veiga Filho, ${ }^{6}$ desde 1808 pretendeu-se criar este imposto no Brasil. Houve várias propostas neste sentido, todas elas sem sucesso. Segundo o mesmo autor, a comissão que, em 1832, deu parecer sobre a proposta de orçamento, lembrou este imposto que, no entanto, não foi instituido. $O$ mesmo tributo foi incluído no projeto de lei de terras, em 1843, que veio a ser rejeitado em 1850, após longa tramitação. Sem mencionar as sugestões de Tavares Bastos, assinalo que os relatórios de 1877 e 1879 do Ministro da Fazenda aconselhavam a criação do imposto, que foi aprovado pela Câmara dos Deputados em 1880, mas rejeitado pelo Senado.

5. American Public Finance, New York, Prentice - Hall, 1942, p. 360.

6. Manual de Sciencia das Finanças, São Paulo, Espindola e Cia., 1906, p. 194 e ss. 
A libertação dos escravos, em 1888, foi um freio à discussão do assunto com à de qualquer outro que levasse à oneração direta ou indireta da lavoura.

A Constituição de 1891 , em seu artigo $9^{\circ}$ inciso $2^{\circ}$ atribuiu aos Estados competência para decretar impostos sobre imóveis rurais e urbanos. As Constituições de 1934, 1937 e 1946, mantiveram o imposto territorial rural na competência impositiva dos Estados. A Emenda n. 5, de 21 de novembro de 1961, à Constituição de 1946, transferiu este imposto para a competência dos Municípios, tendo a Emenda n. 10, de 9 de novembro de 1964, entregue o tributo à competência da União, que o cobraria, entregando o produto da arrecadação aos Municípios. A Emenda n. 18, de 1965, manteve-o na competência da União com o propósito declarado de utilizá-lo como instrumento da reforma agrária. Com os mesmos propósitos, o imposto territorial rural foi mantido na competência da União pela Constituição de 1967, pela Emenda n. 1/69 e pela Constituição de 1988.

O predomínio político dos proprietários rurais não permitiu, durante muito tempo, que o imposto sobre a propriedade rural fosse instituído no Brasil. Ainda em 1917, o Prof. J. J. Cardozo de Mello Neto, em dissertação apresentada nesta Faculdade para concurso de professor substituto, afirmava peremptoriamente que "o imposto territorial, como imposto principal dos Estados, sucedâneo do imposto de exportação, não poderá jamais ser aplicado no Brasil" (p. 39 da tese).

Na verdade, o imposto territorial rural, que só começou a ser cobrado por alguns Estados depois que a Constituição de 1891 lhes atribuiu competência para tanto, jamais foi arrecadado como se presume devesse sê-lo. De resto, o imposto predial e territorial urbano só em época recente começou a ser cobrado com mais rigor e com bases mais aproximadas dos valores reais. Como instrumento de reforma agrária, este imposto revelou-se um fracasso.

O imposto de exportação é, pelo contrário, uma história de sucesso de arrecadação, embora de desastre econômico. A história tributária do Brasil começou com a cobrança da dízima das "mercadorias que às ditas terras forem, ou delas sairem", conforme dizia o Regimento do Provedor-Mor da Fazenda, no Brasil, passado pelo Rei de Portugal, em 17 de dezembro de 1548.

Desde o início, portanto, o imposto de exportação instalou-se no Brasil. No Império, era de importância para as Províncias. Objeto de largo debate na Constituinte de 1890-91, ficou afinal atribuído aos Estados, que o mantiveram, 
até a Emenda n. 18/65 à Constituição de 1946. Em momento algum, deixaram de levantar-se vozes contrárias a este imposto, pelo que representa de antieconômico. Antes mesmo da Independência, José Caetano Gomes, Tesoureiro-Mor do Erário do Rio de Janeiro, em representação ao Príncipe Regente, postulava a abolição dos impostos de exportação. Dizia ele:

"Seja-me permitido dizer a V.A. que esses dois por cento devem ser abolidos.

$\dot{E}$ um tributo estabelecido contra todos os principios da Economia Política, e que as nações mais esclarecidas, e que conhecem os seus verdadeiros interesses, não têm; antes, animam a exportação com prêmios."

Outras opiniões no mesmo sentido poderiam ser invocadas. O projeto da Constituição de 1891 propunha que o imposto de exportação fosse extinto dentro de poucos anos, mas a proposta foi rejeitada. A Constituição de 1934 limitou-o a $10 \%$ ad valorem, em exemplo seguido pela Constituição de 1937. A de 1946 estabeleceu-lhe a alíquota máxima de $5 \%$.

Por fim, a Emenda n. 18/65 subtraiu-o da competência dos Estados atribuindo-o à União, o que é correto. $\mathrm{O}$ imposto de exportação deve ser tributo meramente regulatório, de competência da União, à qual cabe, privativamente, legislar sobre comércio exterior e interestadual (C.F., art. 22, VIII).

A solução foi apenas parcial porque, substancialmente, um imposto o ICM - continuou a ser cobrado pelos Estados nas exportações. A Emenda n. 1/69 resolveu o problema quase integralmente, ao instituir a imunidade, em relação ao ICM dos produtos industrializados destinados ao exterior. A legislação complementar ordenou que os créditos dos insumos dos produtos exportados fossem mantidos, completando a solução.

Quando tudo parecia finalmente assentado, a Constituição de 1988, mantendo a imunidade para os produtos industrializados exportados para 0 exterior, dela permitiu que fossem excluídos os chamados semielaborados. Ao mesmo tempo, estabeleceu que, sendo a exportação imune, não podiam se mantidos os créditos dos insumos, salvo se lei complementar o determinasse. Estava substancialmente reinstituido, em grande parte, um imposto estadual de exportação. 
Que conclusões extrair do que foi dito? Os Estados Unidos, desde cedo, fizeram do imposto sobre a propriedade um dos pilares de sua arrecadação, ao mesmo tempo em que aos Estados era vedado cobrar qualquer tributo nas exportações. Já o Brasil cobrou tardiamente - e mal - o imposto sobre a propriedade rural. Ao mesmo tempo, fez do imposto de exportação um dos sustentáculos de seu sistema tributário, por muito tempo. Ainda hoje, há Estados que não se conformam em não tributar as exportações. Os semielaborados e o aproveitamento dos créditos do ICMS relativos aos insumos dos produtos industrializados são a válvula de escape para a tributação.

Ou seja, o poder político dos proprietários rurais brasileiros levou-os a permitir, só muito tarde, que fosse instituído um imposto sobre suas propriedades, o que forçou o recurso ao imposto de exportação para prover as necessidades do erário. E havia perfeita consciência deste fato. A Comissão dos 21 afirmou na Constituinte de 1891: "O imposto territorial não pode ser adotado em todos os Estados como natural sucedâneo do imposto de exportação..." ?

No tempo do Império, a Sociedade Central de Imigração fez larga propaganda do imposto territorial rural apontando, entre as bases da criação deste imposto, a extinção dos impostos de exportação.

Parece que defeitos e problemas que se acumularam no curso de nossa história ainda se refletem nos dias de hoje. É claro que as discussões que se travam a respeito assumem um pretenso caráter objetivo, baseado em argumentos supostamente racionais. Na verdade, tributar exportações, sob qualquer forma, é manter um imposto de matiz colonial, que mal oculta a substituição de outros que deveriam ser instituídos ou, se existentes, cobrados com eficiência. Não seria nada mau que a história da tributação no Brasil fosse um pouco mais conhecida. Este conhecimento iluminaria a discussão de problemas atuais.

Ressalvo, é claro, que tem perfeito cabimento um imposto de exportação de competência da União, que deverá usá-lo com efeitos meramente regulatórios. Ressalvo, também, que hoje a insistência com a cobrança de um imposto estadual sobre as exportações não está mais ligado apenas à inexistência de um imposto territorial, como no passado, mas à ineficiência - ou falta de vontade política - na arrecadação dos impostos que cabem aos Estados ou, por fim, na

7. Apud J. J. Cardozo de Mello Neto, Dissertação cit., p. 39. 
impossibilidade de Estados deixarem de arrecadar este tipo de tributo, o que nos reconduz ao tema da autonomia.

Creio que os dois exemplos que lhes trouxe hoje, o da receita dos Estados, suas origens e seus problemas e o do imposto de exportação e suas raízes são suficientes para deixar claro que discussões sobre sistema tributário podem ter, para além de uma racionalidade aparente, razões outras que não são especificadas. O exemplo com que ilustro o que digo é o imposto único que se propõe atualmente, com certo alarde. A simplificação e o combate à sonegação constituem sua racionalidade proclamada. No entanto, este chamado imposto único não é, na verdade, único. É antes um feixe de um número indeterminado de impostos que se caracterizam pela unidade do método de arrecadação. Assim, se se tributa o cheque do salário, o que se está onerando é o próprio salário. Se o cheque pagou uma compra, o que se tributa é a compra. Considerando ser previsível tratar-se, na maior parte, de impostos repercutiveis, o que se conclui é que a carga fiscal iria recair indistintamente sobre os preços, com caráter regressivo e, portanto, proporcionalmente mais oneroso para quem vive de rendimentos do trabalho, ou rendimentos fixos em geral. Esta crítica aplica-se ao IPMF A alta regressividade que apontei tem sido uma característica da tributação no Brasil, o que leva a perguntar se a racionalidade da simplificação invocada não cobre outras razões cujas raízes vêm de longe. 